\title{
Study of Different Structural Elements Used For Thin Composite Plate
}

\author{
Ms. Neha V. Potdar. ${ }^{1}$, Prof. Maruti A. Mohite. ${ }^{2}$ \\ ${ }^{I} P G$ Scholar, Mechanical Engineering- Design, Sinhgad Institute of Technology, Lonavla, India \\ ${ }^{2}$ Associate Professor, Mechanical Engineering, Sinhgad Institute of Technology, Lonavla, India
}

\begin{abstract}
Composites are extensively used in aerospace and automotive industry. The requirement usually is to create holes in composite members to facilitate mounting of various members. These holes act as stress concentration regions and the causes of failure. At present, the analytical treatments developed are very restrictive to particular cases. Thus to analyze complex hole patterns subjected to tensile loadings there is necessity of FEA software. FEA tool offers different structural elements for analysis, each with different number of nodes. Engineer has to shortlist the elements and need to carryout permutations for selecting suitable element for analysis. Thus study of these different elements is carried out as part of this paper. Different Structural Finite elements are thus studied and applied to a model under study for tensile loading condition. The results of FE Analysis are validated against analytical solution and best fit Structural element is suggested at the end if paper. Scope of this study is limited to graphitelepoxy composites and can be extended further.
\end{abstract}

Keywords: composite, FEA, ANSYS, Structural, Nodes

\section{Introduction}

In recent years composite materials are extensively used in various fields of life from automotive, aerospace industry to sports industry. Composites have proven their importance even in the field of medical science like dentures. Their higher mechanical properties in contrast to light weight keep them on high demand.

Being an orthotropic material it shows higher 'directional mechanical properties', higher strength and stiffness combined with low density.[1]

Theories developed for analysis of isotropic material don't give good results for composite material. A numerical analysis of composite component becomes difficult as the theories developed for orthotropic material are complex in nature. Micro detailed level analysis is more complex, compromising accuracy of results. Finite Element Analysis thus proves accurate and fast solution for complex problems of orthotropic structures.[1]

\section{Analysis}

ANSYS is widely used software tool to carry out such complex Finite Element Analysis. It offers sets of elements for single as well as Multi-Dimensional analysis. e.g. PLANE42 for 2-D analysis, SOLID185 for 3D Analysis. Every element offered by software has its own accuracy and suitability for a type of application, material and analysis. Table given below has exhaustive list of structural elements used in ANSYS. [2,3]

\begin{tabular}{|c|c|c|c|}
\hline Nodes & 2-D Elements & \multicolumn{2}{|c|}{ 3-D Elements } \\
\hline & PLANE & SHELL & SOLID \\
\hline \multirow{2}{*}{ 4- Node } & \multirow{2}{*}{ PLANE42 } & SHELL43 & \\
\cline { 3 - 4 } & & SHELL181 & \\
\hline \multirow{2}{*}{ 8-Node } & PLANE82 & SHELL93 & SOLID45 \\
\cline { 3 - 4 } & & & SOLID185 \\
\hline 10-Node & & & SOLID187 \\
\hline
\end{tabular}

The aim of this paper is to study structural elements available with ANSYS Software and to select the suitable structural Element for FEA of a composite plate with central circular hole. For this purpose a thin composite plate of Graphite/Epoxy Composite with dimension $100 \mathrm{~mm}$ x $300 \mathrm{~mm} \times 5 \mathrm{~mm}$ is chosen shown in Fig.1.

Analytical treatments were carried out with reference to Whitney-Nuimer's Model. Simulations were performed with the help of ANSYS Parametric Design Language. The specimens were modeled with different Structural elements (Table 1) and the Stresses in Y direction are compared with stress calculated analytically. 
The Structural element for which stresses follow theoretically calculated values is selected a suitable structural element for further FEA.

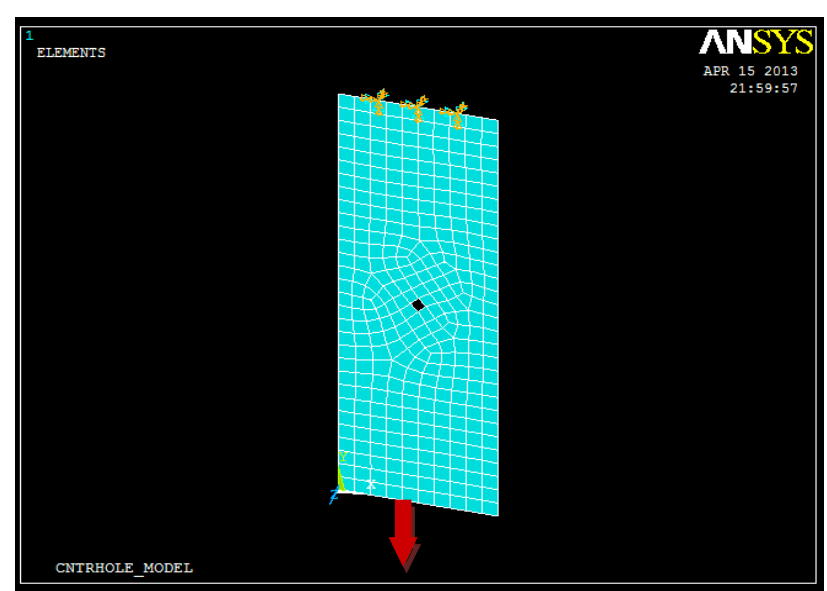

Fig.1. Composite Laminate with central Hole under study with Boundary Conditions

\section{Analytical And Numerical Treatment}

There are some analytical approaches available to calculate the stress in Y direction along Y center of the hole. The Theory was developed by Whitney-Nuimer's and was referred for the study of stress concentration around hole for carbon/epoxy composites [4]. Current study focuses at graphite/epoxy composites and hence the analytical as well as FEA treatment is important to carry out.

\subsection{Analytical Approaches}

Fig. 2 shows theoretical arrangement of plate and load considered for analytical approach[4] while Table. 2 shows the tensile mechanical properties of a composite under study.

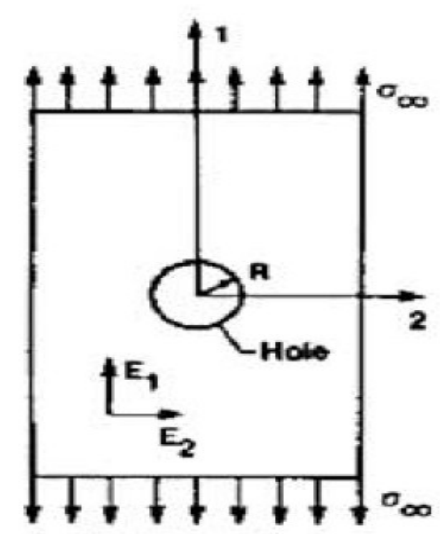

Fig. 2 - Theoretical arrangement of plate and its Mechanical Properties

\begin{tabular}{|c|c|c|c|c|c|}
\hline $\mathbf{E} 1\left(\mathbf{N} / \mathbf{m m}^{2}\right)$ & $\mathbf{E 2}\left(\mathbf{N} / \mathbf{m m}^{2}\right)$ & $\mathbf{v 1 2}$ & $\mathbf{G}_{12}\left(\mathbf{N} / \mathbf{m m}^{2}\right)$ & $\begin{array}{c}\text { Thickness } \\
\mathbf{t}(\mathbf{m m})\end{array}$ & $\begin{array}{c}\text { Hole Radius r } \\
(\mathbf{m m})\end{array}$ \\
\hline 7170 & 158500 & 0.32 & 3440 & 5 & 5 \\
\hline
\end{tabular}

Table 2: Tensile properties of Graphite / Epoxy under study

Consider a circular hole of radius $r$ in an infinite anisotropic plate as shown in Fig. 1. If the remote uniform stress $\sigma \infty$ is applied in the y-axis direction, then the normal stress $\sigma y$ in the y-axis direction at the point on the $\mathrm{x}$-axis in front of the hole may be approximated by: [4]

$\sigma \mathrm{y}(\mathrm{x}, 0)=\frac{\sigma \infty}{2}\left\{2+(\mathrm{r} / \mathrm{x})^{2}+3(\mathrm{r} / \mathrm{x})^{4}-(1+n-3) *\left[5(\mathrm{r} / \mathrm{x})^{6}-7(\mathrm{r} / \mathrm{x})^{8}\right]\right\}$

Where, $x>r \quad \&$

$n$ is obtained by, 
$n=\sqrt{2\left(\frac{E 1}{E 2}-2 v 12\right)+\left(\frac{E 1}{G 12}\right)}$

At the hole boundary $(x-r)$, Eq. (1) gives the stress concentration factor:

$K=\frac{\sigma y(r, 0)}{\sigma \infty}-1+n$

Eq. (3) gives a constant value of $\mathrm{K}$ for the same material regardless of the hole size. As the hole size decreases, the stress concentration factor decreases and finally approaches unity (that is, a plate without a hole). Two stress criteria for predicting circular holes and straight cracks, namely the "point stress" criterion and the "average stress" criterion proposed by Whitney and Nuismer was used to calculate failure stress values.[4]

\subsubsection{Point stress criterion (PSC)}

The point stress criterion assumes that the failure will occur when the stress $\sigma \mathrm{y}(\mathrm{x}, 0)$ at a certain small fixed distance $\mathrm{d} 0$ ahead of the hole boundary first reaches the tensile strength of of the material (or tensile strength of the plate without a hole) Fig. 7. It is expressed in the following equation:

$K p s c=\frac{\sigma y}{\sigma \infty}=\frac{1}{2}\left\{2+\varepsilon^{2}+3 \varepsilon^{4}-(1+\mathrm{n}-3) *\left[5 \varepsilon^{6}-7 \varepsilon^{8}\right]\right\}$

where, $\varepsilon=\frac{\mathrm{r}}{\mathrm{r}+\mathrm{do}}$

\subsubsection{Average stress criterion (ASC)}

The average stress criterion assumes that the failure will occur when the average value of $\sigma \mathrm{y}(\mathrm{x}, 0)$ over some small fixed distance ao ahead of the hole boundary first reaches the tensile strength of of the material Fig. 7. It is expressed in the following equation:

Kasc $=\frac{\sigma y}{\sigma \infty}=\frac{1}{2(1-\xi)}\left\{2-\xi^{2}-\xi^{4}-(1+\mathrm{n}-3) *\left[\xi^{6}-\xi^{8}\right]\right\}$

where, $\xi=\frac{\mathrm{r}}{\mathrm{r}+\mathrm{ao}}$

The Coefficients of Stress Concentration factors and stress $\sigma y$ is calculated from above formulae. Results of this analytical treatment are tabulated in Table- 3 and Table- 4 below.

\begin{tabular}{|c|c|}
\hline \multicolumn{2}{|c|}{ Coefficient of Stress Concentration } \\
\hline Point Stress Criterion $\left(\mathrm{K}_{\mathrm{psc}}\right)$ & 2.10 \\
\hline Average Stress Criterion $\left(\mathrm{K}_{\text {asc }}\right)$ & 2.79 \\
\hline
\end{tabular}

Table 3: Coefficient of Stress Concentration Based on Whitney-Nuimer's Model

\begin{tabular}{|l|c|}
\hline Based on remote Uniform Stress, $\boldsymbol{\sigma y}\left(\mathbf{N} / \mathbf{m m}^{\mathbf{2}}\right)$ & 4.016 \\
\hline Based on Point Stress Criterion, $\boldsymbol{\sigma y p s c}\left(\mathbf{N} / \mathbf{m m}^{\mathbf{2}}\right)$ & 4.19 \\
\hline Average Stress Criterion, $\boldsymbol{\sigma y a s c}\left(\mathbf{N} / \mathbf{m m}^{\mathbf{2}}\right)$ & 5.58 \\
\hline
\end{tabular}

Table 4. Analytical values of Stress in "Y" Direction

\subsection{Numerical (FEA) Approach}

ANSYS has Variety of Structural elements. The difference of elements lies in number of Nodes present in the element. There are 4 Node, 8-Node, 10-Node elements available with ANSYS. Mid-Side node available for an element gives accuracy and flexibility in its use. To analyze the accuracy of these different structural elements a model for the analysis is developed as shown in Fig.1 with the help of In ANSYS Parametric Design Language. Analysis is carried out for different structural elements available. Results are tabulated below in Table.5 


\begin{tabular}{|c|c|c|c|}
\hline & \multicolumn{3}{|c|}{ PLANE ELEMENTS } \\
\hline & \multicolumn{2}{|l|}{ PLANE42 } & PLANE82 \\
\hline \multirow[t]{3}{*}{$\sigma \mathrm{y}\left(\mathrm{N} / \mathrm{mm}^{2}\right)$} & \multicolumn{2}{|l|}{25.807} & 25.807 \\
\hline & \multicolumn{3}{|c|}{ SHELL ELEMENT } \\
\hline & SHELL43 & SHELL93 & SHELL181 \\
\hline \multirow[t]{3}{*}{$\sigma y\left(\mathrm{~N} / \mathrm{mm}^{2}\right)$} & 6.751 & 6.987 & 5.482 \\
\hline & \multicolumn{3}{|c|}{ SOLID ELEMENT } \\
\hline & SOLID45 & SOLID185 & SOLID187 \\
\hline$\sigma y\left(\mathrm{~N} / \mathrm{mm}^{2}\right)$ & 25.318 & 16.99 & 25.428 \\
\hline
\end{tabular}

Table 5. FEA results of Stress in "Y" Direction for Different Structural Elements

\section{Results And Discussions}

When Analytical as well as FEA results are compared for Stress in Y Direction $\left(\sigma_{\mathrm{y}}\right)$ the FEA results of Shell elements are in accordance with the Analytical results. Out of the three types of SHELL Elements, results for SHELL181 lies close to the analytical results and hence SHELL181 is selected for analysis of Graphite/Epoxy plate under study.

SHELL181 is 8-Node Shell element which is having midside node capability, the deformation shapes are quadratic in both in-plane directions. The element has nonlinear and large strain capabilities. These Capabilities of SHELL181 makes it suitable for analysis of Composite Plate.

\section{Conclusion}

This study of different structural elements under tensile load condition reveals that the FEA results for thin composite plate with SHELL181 are in good agreement with analytical solutions for the plate. Thus, for this analysis SHELL181 is suitable structural element. Presence of mid-side node makes this shell element accurate and suitable for this analysis.

\section{References}

[1]. Ever J Barbero, "Finite Element Analysis of Composite Materials", CRC Press, Year-2011, page No: 1-105

[2]. Y.X. Zhang, C.H. Yang, "Recent developments in finite element analysis for laminated composite plates", Composite Structures, vol. 88, page No. 147-157, year 2009

[3]. Lotfi Toubal, Moussa Karama, Bernard Lorrain, "Stress concentration in a circular hole in composite plate," Composite Structures, vol. 68, page No. 31-36, year 2005

[4]. Bryan Harris, "Engineering Composite Materials", London, Year-1999, page No: 1-20, 30 -130 